\title{
Disputas conceituais e metodológicas na concepção de um projeto de ATER para cooperativas de agricultores familiares
}

\author{
Conceptual and methodological disputes in conception of an ATER project to cooperatives of \\ family farmers
}

Disputas conceptuales y metodológicas en el diseño de un proyecto ATER para cooperativas de agricultores familiares

Recebido: 14/09/2020 | Revisado: 16/09/2020 | Aceito: 07/03/2021 | Publicado: 14/03/2021

\author{
Marcos Roberto Pires Gregolin \\ ORCID: https://orcid.org/0000-0003-0943-5337 \\ Universidade Federal de Santa Maria, Brasil \\ E-mail: marcosgregolin@yahoo.com.br \\ Renato Santos de Souza \\ ORCID: https://orcid.org/0000-0002-0984-6307 \\ Universidade Federal de Santa Maria, Brasil \\ E-mail: renatosdesouza@gmail.com
}

\begin{abstract}
Resumo
Este estudo, realizado por meio de pesquisa documental, bibliográfica e observação participante, aborda o Projeto de ATER Mais Gestão para cooperativas de agricultores Familiares e busca evidenciar, tendo por base elementos materializados em seus documentos orientadores, a disputa protagonizada entre ênfase participativa e ênfase impositiva. Tal disputa muito se assemelha ao debate feito de diferenciação entre processos de extensão rural e ações de assistência técnica. Este trabalho salienta a existência de forças antagônicas que transitam para direções opostas, principalmente ao se analisar as características dos empreendimentos atendidos e as propostas de ações. Por fim, sugere-se ou uma alteração drástica na concepção do projeto ou a mudança no tipo de organização público-alvo.
\end{abstract}

Palavras-chave: Cooperativismo; Aprimoramento; Assistência técnica; Extensão rural.

\begin{abstract}
This study, carried out through documentary, bibliographic research and participant observation, aimed to analyse the ATER Mais Gestão Project for cooperatives of family farmers and seeks to show, based on elements materialized in its guiding documents, a dispute between participatory and imposing emphasis. This dispute is very similar to the debate made on the differentiation between rural extension processes and technical assistance actions. This research highlights the existence of antagonistic questions that move to the opposite directions, mainly when analyzing the characteristics of the industry served and the proposals for actions. Finally, a drastic change in the design of the project or a change in the type of target audience organization is mandatory.
\end{abstract}

Keywords: Cooperativism; Enhancement; Technical assistance; Rural extension.

\section{Resumen}

Este estudio, realizado a través de la investigación documental, bibliográfica y la observación participante, acércase al Proyecto ATER "Mais Gestão" para las cooperativas de agricultores familiares y busca resaltar, a partir de elementos materializados en sus documentos norteadores, la disputa entre el énfasis participativo y el énfasis imponente. Tal disputa es muy similar al debate sobre la diferenciación entre procesos de extensión rural y acciones de asesoría técnica. Este trabajo subraya la existencia de fuerzas antagónicas que se mueven en direcciones opuestas, principalmente al analizar las características de las empresas atendidas y las propuestas de acción. Finalmente, se sugiere una modificación drástica en el diseño del proyecto o un cambio en el tipo de organización del público-meta.

Palabras clave: Cooperativismo; Mejoramiento; Asesoría técnica; Extensión rural.

\section{Introdução}

O trabalho que segue abrange as diferentes fases da implementação do Projeto "Mais Gestão", iniciando pelo ajuste da proposta ao formato das "chamadas públicas", seguindo pela análise crítica da adequação da orientação e posteriormente das recomendações. No que tange o ajuste da proposta ao formato das chamadas públicas, retoma-se a discussão da Lei ${ }^{\circ}$ 
12.188 com o intuito de caracterizar brevemente a modalidade de implementação dos serviços de ATER após a sua promulgação. Esta Lei institui que o Programa Nacional de Assistência Técnica e Extensão Rural na Agricultura Familiar e Reforma Agrária - PRONATER é o principal instrumento para operacionalização da PNATER. Caracterizam-se como entidades executoras do PRONATER, "instituições ou organizações públicas ou privadas, com ou sem fins lucrativos, previamente credenciadas na forma desta Lei" (Brasil, 2010, Art. 11), as quais serão previamente selecionadas por meio de chamada pública.

Para Grisa e Wesz Junior (2010) por mais que a PNATER priorizasse a contratação de instituições públicas para a execução de serviços, com o advento das chamadas públicas tornou-se possível "uma assessoria mais adequada às especificidades regionais" dos agricultores familiares, principalmente pelo fato de poder contratar, dentro dos parâmetros legais e sem ferir a lei 8.666 de 1993, cooperativas de técnicos, ONGS e outras instituições com foco de atuação na extensão rural.

Salienta-se que a referida Lei não estabelece critérios de avaliação dos serviços, dispondo apenas que "a metodologia e os mecanismos de acompanhamento, controle, fiscalização e avaliação dos resultados obtidos com a execução de cada serviço contratado serão objeto de regulamento" (Brasil, 2010, Art. 24). Ademais, acredita-se que a nova roupagem da ATER (chamadas, contato, monitoramento por meta física, cronograma engessado) tem prejudicado gravemente o alcance de resultados verdadeiramente impactantes na realidade atendida.

“A Nova Extensão Rural, assimila, como forma de organização e legitimação legal, o padrão organizativo do Estado burocrático moderno, assumindo a burocracia moderna como forma de organização social e administrativa e de legitimação perante a sociedade (Corandin \& Souza, 2017, p. 121). Para Diniz, Lima e Almeida (2011) as chamadas públicas, ao menos nessa avaliação inicial, se caracterizaram como instrumentos focalizados mais na "assistência técnica" do que na "extensão rural", se afastaram do caráter educativo tido como ponto central nas discussões da PNATER e não proporcionaram um ambiente de capacitação e permanência das equipes técnicas, características estas tidas pelos autores como negativas e fragilizadoras do processo.

A respeito dos beneficiários do projeto "Mais Gestão", nota-se que cada uma das chamadas publicadas (04/2012 ; 06/2012;07/2012 e 17/2013) para contratação de entidades executoras teve especificidades, porém, é unânime que as organizações para receber atendimento do "Mais Gestão" devem ser "cooperativas da agricultura familiar detentoras de DAP Jurídica", salvo as assistidas por outros projetos em execução celebrados com o governo federal cujo objetivo seja o mesmo e que o MDA poderá indicar um percentual delas para atender critérios de priorização de gênero, raça, etnia, renda ou outros. Salienta-se que compreender as especificidades da agricultura familiar bem como de seus empreendimentos e diagnosticar os melhores arranjos para a inserção dos produtos, tanto em mercados públicos como privados "é condição para o sucesso" da agricultura familiar de acordo com documentos do "Mais Gestão" (DATER, 2012b). No conjunto das 04 chamadas públicas somou-se a oferta de atendimento para 546 cooperativas.

A operacionalização do projeto, tendo por base a metodologia proposta, ocorreu em distintas etapas, algumas padronizadas para todas as organizações, tais como, mobilização, adesão, diagnóstico e elaboração de planos de aprimoramento. As visitas técnicas, que deviam ser executadas respeitando as peculiaridades de cada organização, foram pensadas para proporcionar discussões e encaminhamentos de soluções aos entraves visualizados nas etapas anteriores. Por fim, o "encontro final de avaliação" teve por objetivo reunir os beneficiários, os prestadores do serviço e representantes do contratante para avaliar o trabalho executado e propor encaminhamentos futuros.

Neste trabalho se objetiva avaliar o referencial metodológico da ação extensionista no caso do projeto "Mais Gestão", tido por diversos autores como pioneiro e inovador principalmente pelo fato de se constituir como uma iniciativa inédita de ATER para organizações da Agricultura Familiar (Ávila et al., 2015; Souza, 2015). A análise se dará tendo por base as 
orientações metodológicas e posturas recrutadas aos agentes executores. Por fim se apresentam algumas conclusões, também de caráter preliminar e sugestões ou encaminhamentos de outras pesquisas referentes ao tema.

\section{Metodologia}

Este trabalho se valeu de uma abordagem qualitativa, sustentada por pesquisas bibliográficas, documental e observação participante. Pode ser também classificada como pesquisa aplicada, pois de acordo com Gerhardt \& Silveira (2009) busca gerar conhecimentos aplicáveis e dirigidos a solucionar problemas. Tendo por base os objetivos da pesquisa, a classificamos como descritiva, pois de acordo com Gil (2008) busca descrever as características de determinados fenômenos, e geralmente é empreendida por pesquisadores preocupados com sua atuação prática.

A pesquisa bibliográfica foi realizada principalmente buscando temas relacionados ao cooperativismo. Buscou-se além de conceitos e teorias, estudos e conclusões de outros pesquisadores sobre o universo pesquisado, haja vista que

Pesquisa alguma parte hoje da estaca zero. Mesmo que exploratória, isto é, de avaliação de uma situação concreta desconhecida, em um dado local, alguém ou um grupo, em algum lugar, já deve ter feito pesquisas iguais ou semelhantes, ou mesmo complementares de certos aspectos da pesquisa pretendida. Uma procura de tais fontes, documentais ou bibliográficas, toma-se imprescindível para a não duplicação de esforços, a não "descoberta" de ideias já expressas (Marconi \& Lakatos, 2003, p. 225).

Recorreu-se também para a análise das chamadas públicas do projeto "Mais Gestão", procedimento este que permite classificar a pesquisa como documental. Para Gerhardt e Silveira (2009), pesquisas documentais recorrem a fontes diversificadas como documentos internos e oficiais, relatórios de empresas e demais que não possuem tratamento analítico, e buscam nestes documentos informações relevantes para se atender os objetivos estabelecidos.

Tendo por base a grande similaridade entre as chamadas públicas, situação está que se constatou por meio da leitura de quatro delas, optou-se por padronizar a referência a chamada 06/2012.

Dada a participação de um dos autores como técnico, optou-se por considerar a observação participante como uma fonte de informações para a composição deste trabalho. Esta observação levou em consideração a atuação em 25 cooperativas, localizadas no estado do Paraná e 32 em Santa Catarina, como extensionista contratado pela Agência de Desenvolvimento do Extremo Oeste do Paraná - ADEOP. Segundo Marconi e Lakatos (2003), a observação é uma técnica que utiliza os sentidos, e não só o ver e ouvir, "ajuda o pesquisador a identificar e obter provas a respeito de objetivos sobre os quais os indivíduos não têm consciência, mas que orientam seu comportamento" (Marconi \& Lakatos, 2003, p. 191). Esta observação proporcionou ricos elementos que auxiliaram na construção das reflexões apresentadas no trabalho.

\section{Resultados e Discussão}

\subsection{Características do cooperativismo da agricultura familiar no sul do Brasil}

Diversos autores convergem com o apontamento de Duarte Wehrmann (2006) de que houve no cooperativismo brasileiro uma divisão no final do século $\mathrm{XX}$ a qual resultou em dois grupos distintos, um denominado de "empresarial/tradicional" e outro de "popular/de resistência". Nota-se que diferentes nomenclaturas ou denominações são atribuídas para as cooperativas de agricultores familiares, principalmente as que vêm se opondo ao cooperativismo tido como "empresarial/tradicional". Adjetivos como solidário, popular de resistência, coletivistas ou substantivas podem conotar, dentre outros significados, que estas organizações alternativas se vinculam com princípios como o de solidariedade, equidade, inclusão e justiça social e que estas organizações estão "contribuindo com o exercício da democracia e cidadania para todos e todas e a transformação da realidade brasileira" (Rech, 2012, p. 17). 
Ávila et al. (2015) apresentam a contextualização do cooperativismo "forte no espaço rural brasileiro" e sua gênese relacionada com a chegada dos imigrantes europeus no final do século XIX e início do século XX. Tais cooperativas, fundadas nos primórdios da colonização, sobretudo a italiana e alemã, principalmente no sul do país, se prestaram com eficiência a propagação e instalação do ideário da modernização agrícola e se estabeleceram como representantes hegemônicas do cooperativismo por um longo período de nossa história recente (Frantz, 2012). O movimento cooperativo de bases populares na agricultura familiar, por sua vez, é mais recente, e tem sua origem principalmente vinculada ao "Movimento dos Sem Terra (MST) e outras organizações políticas ligadas a agricultura familiar somente a partir de 1989” (Ávila et al., 2015, p. 08).

Em específico, quando se fala em cooperativismo solidário, retoma-se um conceito de economia solidária, que para Silva (2015) é composta por atividades distintas, podendo envolver processos de produção, distribuição, consumo, crédito dentre outros, sempre, se valendo das seguintes características: cooperação, autogestão, viabilidade econômica e solidariedade. Já para o estudo de Severo \& Pedrozo (2008) em uma cooperativa de agricultores familiares, ao se analisar 10 dimensões da racionalidade, comparando entre instrumental e substantiva, 07 delas são guiadas mais fortemente pela razão instrumental substantiva, tendo por base a proposta de Guerreiro Ramos. Contudo, por mais que seja depositado nestas organizações uma esperança por melhores condições de vida, "sem os adequados conhecimentos, os agricultores não chegavam a constituir maior poder de ação em suas organizações cooperativas" (Frantz, 2012, p. 98).

Tendo por base outro referencial, estudos como o de Christoffoli (2000) focado em cooperativas de agricultores familiares assentados buscou analisar dimensões organizacionais como autoridade, normas, controle social, relações sociais, recrutamento e promoção, estrutura de incentivos, estratificação social e diferenciação e nos permite concluir que a configuração dessas organizações cooperativas tende a se assemelhar com o modelo de organização coletivista apresentado por Rothschild-Whitt (1979).

Observa-se ainda a emergência de um conjunto de empreendimentos que foram constituídos muito por apoio ou por incentivo de políticas públicas, cabe citação neste caso o PRONAF, PRONAF INFRAESTRUTURA, PRONAT, PROINF e mais recentemente o PAA e PNAE, programas estes que se não tornaram exclusivo, priorizaram o acesso aos mercados institucionais por meio de organizações e não de agricultores individuais, inicialmente, cabendo a associações para em momentos posteriores dar-se a preferência de acesso para cooperativas. Para Freitas e Freitas (2011) com a criação do PRONAF o estado passou a, mesmo que de maneira sutil, a fomentar a criação dessas organizações, e para os autores, esta criação instrumental para o acesso a políticas públicas ou simplesmente como resposta direta ao contexto conjuntural favorável impõem geralmente fragilidades na organicidade destes empreendimentos.

a constituição e ou formalização de organizações locais como instrumento de acesso a recursos financeiros e a políticas públicas, pode levar à formação de empreendimentos meramente formais e socialmente desenraizados, uma vez que a coesão social do grupo não propicia a formação de relações de cooperação e de sua apropriação integral. Portanto, pode gerar organizações desenraizadas e utilitaristas (Freitas \& Freitas, 2011, p. 264).

O reconhecimento das diferenças entre estes segmentos do cooperativismo levou, inclusive, a colocar em evidência a forma tradicional de representação política do setor. O Cooperativismo como um todo e inclusive as organizações alternativas mencionadas anteriormente, por via de Lei é representado pela Organização das Cooperativas do Brasil (OCB), uma "sociedade civil, com sede na Capital Federal, órgão técnico-consultivo do Governo, estruturada nos termos desta Lei, sem finalidade lucrativa" (Brasil, 1971, artigo 105), a qual desde sua criação em 1969, durante o IV Congresso Brasileiro de Cooperativismo, atuou de maneira hegemônica neste campo (Mendonça, 2005). Porém em meados de 1990 surgem discussões sobre a representatividade da OCB, principalmente no que concerne as cooperativas menores, pouco atuantes em grandes mercados, guiadas ou condicionadas a atuação em âmbito local e em cadeias curtas, baseadas com mais ênfase em princípios 
de solidariedade do que em eficiência econômica, diga-se de passagem, valores estes que deveriam permear a racionalidade de todas as cooperativas, como afirma Lauschner (1994) "seja qual for o tipo de cooperativa, o cooperativismo é um modelo de economia solidária" (Lauschner, 1994, p. 03).

Foi no bojo de reflexões como esta que se materializa no âmbito da agricultura familiar e de suas organizações a discussão do cooperativismo de economia solidária, a qual ganhou forças em 2005 com a criação da União Nacional das Cooperativas da Agricultura Familiar e Economia Solidária (UNICAFES) (Silva, 2006; Santos \& Silva, 2015).

\subsection{A seleção e perfil das cooperativas beneficiárias do MAIS GESTAO}

Para participação como beneficiárias no projeto as cooperativas deveriam atender requisitos formais e processuais. Quanto aos requisitos formais, se estabeleceu que as cooperativas, público alvo deste projeto, além de serem formadas por agricultores familiares e detentoras de DAP Jurídica, deveriam, prioritariamente ou preferencialmente possuir relações com o mercado, em específico com os programas de compras institucionais. Pode-se imaginar que este requisito constituiu um divisor destas organizações com aquelas que ao longo do tempo, se estabeleceram como cooperativas de pequenos agricultores, porém que se especializaram na recepção, classificação e comercialização de monoculturas, como trigo, soja e milho e também na comercialização de insumos agrícolas, as quais em uma observação preliminar não lançaram mão do direito de participarem nos mercados institucionais.

Quanto aos requisitos processuais, o atendimento para as cooperativas só poderia acontecer depois que elas recebessem uma visita da equipe técnica e lhes fosse apresentado o projeto. Ressalta-se que as cooperativas tinham liberdade de aceitar ou não a participação. Coube para as concordantes a assinatura de um termo de adesão e responsabilidade, no qual também manifestavam ciência de que o serviço era gratuito e que qualquer reclamação poderia ser encaminhada para o MDA. Na medida em que as cooperativas prioritárias não aderiam ao projeto, buscaram-se cooperativas da lista de suplentes.

Para selecionar as cooperativas da agricultura familiar dos estados do Paraná e Santa Catarina, atendidas no seio da chamada 06/2012, foram realizadas audiências com instituições ligadas à agricultura familiar, bem como FETAEP, FETAESC, FETRAF, EMATER, EPAGRI, INCRA, MDA, UNICAFES e outras, onde se construiu uma lista de cooperativas, compreendendo as titulares ( 25 no Paraná e 32 em Santa Catarina) e algumas suplentes. Acredita-se que em se tratando de indicação por parte das instituições acima apresentadas as cooperativas indicadas poderiam ter se sentido na obrigação de aceitar o atendimento, mesmo elas não estando preparadas ou minimamente relacionadas com o mercado da maneira que o projeto suscitava.

\subsection{A adequação da metodologia do "Mais Gestão" na geração de recomendação contextualizada}

Busca-se neste fragmento do texto relacionar alguns aspectos do projeto "Mais Gestão", tendo por base a análise de documentos institucionais e a observação participante realizada durante a sua execução, com os referenciais metodológicos do enfoque participativo.

Como já referenciado anteriormente, nota-se por meio da leitura dos editais do projeto "Mais Gestão" que houve citações e apontamentos sobre relação dialética e dialógica entre os técnicos e agricultores, fomento a problematização da realidade vivenciada por estes, geração e socialização de conhecimentos, mobilização comunitária e protagonismo do público beneficiário como agentes do desenvolvimento sustentável. Na medida em que se segue com a leitura dos editais de chamada pública nota-se que todo o projeto parte de um pressuposto geral, por meio do qual se chega à conclusão de que os empreendimentos da agricultura familiar 
apresentam fragilidades do ponto de vista gerencial, identificadas pela baixa qualificação em ferramentas de gestão e a inexistência de investimentos em modernização de seus processos para a agregação de valor aos seus produtos. Estas fragilidades acabam gerando ineficiência e instabilidade num momento de expansão de acesso aos mercados (Dater, 2012b, p. 03).

Nota-se que tal entendimento também se manifesta na literatura, ao exemplo do texto já apresentado e discutido de Ávila, Caldas e Assad (2013) dentre outros diversos que abordam as dificuldades de comercialização e gestão dos agricultores familiares e seus empreendimentos. Ao se levar em consideração tal prerrogativa do edital, pode-se concluir que para o "Mais Gestão" a modernização, tanto nos processos de agregação de valor quanto nos processos gerenciais, bem como a aplicação de ferramentas de gestão é condicionante ao bom andamento dos empreendimentos da agricultura familiar.

A metodologia ATER Mais Gestão é uma metodologia singular e com uma abordagem multidisciplinar que permite a identificação e solução de problemas técnicos gerenciais e tecnológicos, a fim de incrementar a competitividade e promover a cultura de sustentabilidade social e econômica nos empreendimentos da agricultura familiar (DATER, 2012b, p. 03).

Nota-se o entendimento, de acordo com a caracterização do projeto, de que uma cooperativa, para ser promissora precisa ser eficiente e para isso ela deve implementar soluções, de caráter gerenciais e tecnológicos para se tornar uma organização competitiva. Nota-se que expandir os mercados é uma das centralidades do "Mais Gestão" e que inclusive, tendo por base a origem histórica do projeto, os documentos fundamentadores e algumas questões do diagnóstico, esta expansão pode se dar buscando comércio exterior.

Também se pode analisar que por meio do fragmento supracitado a concepção de desenvolvimento é limitada ao social e econômico, situação esta que torna as expectativas descoladas dos conceitos de desenvolvimento sustentável, o qual de fato é interpretado e proposto por diversos autores e de maneiras diferentes, contudo, uma das versões mais simplistas do conceito se refere ao tripé da sustentabilidade, composto pelos dois vieses apresentados acrescido do desenvolvimento ambiental.

O demasiado caráter mercadológico, o qual talvez demonstra a expectativa do projeto em trabalhar com cooperativas dotadas de racionalidade instrumental pode ser notado por meio dos critérios de seleção dos empreendimentos, os quais além de possuir Declaração de Aptidão ao PRONAF - DAP Jurídica devem possuir "estrutura e organização para atender as demandas dos mercados (...) priorizando-se as que tenham experiência com comercialização” (DATER, 2012b, p. 03). Esta racionalidade bem como esta estrutura organizacional para atender as demandas de mercado será tratada posteriormente durante este texto.

\subsubsection{Pré-Diagnóstico}

A primeira ferramenta para coleta de informações das equipes de extensão foi denominada de pré-diagnóstico. Esta ferramenta tinha como finalidade buscar informações de temas relacionados à estrutura organizacional, características dos associados e da base produtiva, recursos humanos envolvidos no empreendimento, produtos e valores comercializados em tipos de mercados, estruturas de agroindustrialização, estruturas disponíveis para a logística, aspectos fiscais e tributários, acesso a políticas públicas, despesas, receitas e investimentos realizados nos últimos anos e vendas e marketing.

De acordo com a própria ferramenta, seu objetivo era de angariar informações que seriam posteriormente utilizadas para definir o perfil geral da gestão da cooperativa antes da realização do Diagnóstico. Pode-se concluir nesse sentido que a principal função desta ferramenta era de aproximar a equipe de técnicos do empreendimento a ser atendido e obter informações gerais, as quais, posteriormente seriam sumarizadas no diagnóstico, que de fato, parece ser a principal ferramenta utilizada para 
a leitura do empreendimento e posterior planejamento de ações. Salienta-se que houve instrução para os técnicos de que algumas questões que constavam no pré-diagnóstico talvez não fossem plausíveis de preenchimento, haja vista a recente aproximação do extensionista com os diretores e funcionários da cooperativa, o que, de acordo com os gestores do "programa", implicaria em falta de vínculo entre estes o que dificultaria a conquista de informações como canais de mercado, valores comercializados, e situação patrimonial da cooperativa, por exemplo.

Nota-se também que em muitos dos casos os técnicos anotaram em seus relatórios que as cooperativas não possuíam dados sistematizados para que lhes possibilitasse preencher alguns campos como: "características dos associados e base produtiva"; "estrutura de agroindustrialização"; "logística e distribuição", "finanças e custos" e "vendas e marketing" ao passo que em outros campos, houve necessidade de realizar adaptações na ferramenta para que ela pudesse comportar observações sobre a realidade que se apresentava de maneira discrepante ao que se esperava retratar no formulário.

Tal situação pode conotar, por um lado, que a ferramenta era, ou demasiadamente engessadas e não condizia com a realidade, ou com a diversidade, do grupo de empreendimentos, ou que as cooperativas não dispunham de tais informações estariam em uma situação muito inferior ao que se esperava dos empreendimentos. Tenciono o entendimento de que a ferramenta padronizada, fechada, não se adapta a realidade dos empreendimentos atendidos, primeiramente pelo seu caráter diferenciado no âmbito do cooperativismo tradicional e em segundo lugar por se tratar de uma ferramenta padrão para se realizar uma fotografia de um leque muito diferenciado de empreendimentos, os quais adotam além das características relativas ao seu segmento, mas também aspectos culturais, regionais, demográficos e outros mais que lhes tornam organizações singulares.

\subsubsection{Diagnóstico}

O formulário de diagnóstico, organizado em seis áreas e trinta subáreas (Quadro 1) trata-se de uma ferramenta com questões fechadas, cujas respostas se aceitava "sim, não, parcial ou não se aplica" e espaços para se anotar observações. Estas respostas, uma vez lançadas no sistema de análise de dados, gera uma matriz de identificação estratégica - MIE. Esse sistema, adaptado para o "Mais Gestão", ponderou as respostas fornecidas pelos beneficiários em cada uma das 260 questões e atribuiu um conceito que retrata a eficiência da cooperativa em todas as 30 subáreas.

Quadro 1. Áreas e Subáreas onde se organizam as questões do diagnóstico do "Mais gestão".

\begin{tabular}{|l|l|}
\hline \multicolumn{1}{|c|}{ GESTÃO ORGANIZACIONAL } & FINANÇAS E CUSTOS \\
\hline GO1-Estratégia Organizacional & FC1-Administração Financeira \\
GO2-Estrutura Organizacional & FC2-Estratégias de Financiamento \\
GO3-Avaliação e Controles Estratégicos & FC3-Indicadores Financeiros \\
GO4-Direção e Participação & FC4-Administração de Custos \\
GO5-Organização do Quadro Social & FC5-Indicadores de Custos \\
\hline \multicolumn{1}{|c|}{ GESTÃO INDUSTRIAL } & \multicolumn{1}{|c|}{ COMERCIALIZAÇÃO E MARKETING } \\
\hline GI1-Produto & CP1-Estrutura de Comercialização \\
GI2-Equipamentos e Utilidades & CP2-Acesso a Mercados Diferenciados e Institucionais \\
GI3-Manutenção & CP3-Comércio Exterior \\
GI4-Matéria prima & CP4-Avaliação de Mercado \\
GI5-Insumos & CP5-Politica Mercadológica \\
GI6-Logística & CP6-Capacidade de Controle e Monitoramento \\
GI7-Processamento & \\
GI8-Gestão da Qualidade & \\
GI9-Seg. do Trabalho e Saúde Ocupacional & \\
\hline GESTÃO DE PESSOAS & GESTÃO AMBIENTAL \\
\hline GP1-Administração de Recursos Humanos & GA1-Regularização Ambiental \\
GP2-Educação e Capacitação & GA2-Política Ambiental \\
GP3-Indicadores de Recursos Humanos & \\
\hline
\end{tabular}

Fonte: Brasil (2014), Autores. 
Cada uma das 260 questões, individualmente, revelou a opinião dos cooperados sobre o status do assunto abordado na entrevista e sistematização do conjunto de respostas (realizada pelo Sistema de Geração de Matriz de Identificação Estratégica - SGMIE) revelou um conceito que ilustra a eficiência da cooperativa em cada subárea, em uma escala tríade, composta por “muito bom”, “bom” ou “ruim”. Esse status é ilustrado na Matriz de Identificação Estratégica, que consiste em uma imagem na qual as subáreas do diagnóstico são apresentadas em quadrantes coloridos, e a dispersão nesses quadrantes é relacionada com o desempenho da cooperativa (dispersão horizontal) e a percepção de importância atribuída pelo técnico (dispersão vertical) da área em questão.

Figura 1. Exemplo de Matriz de Identificação Estratégica.

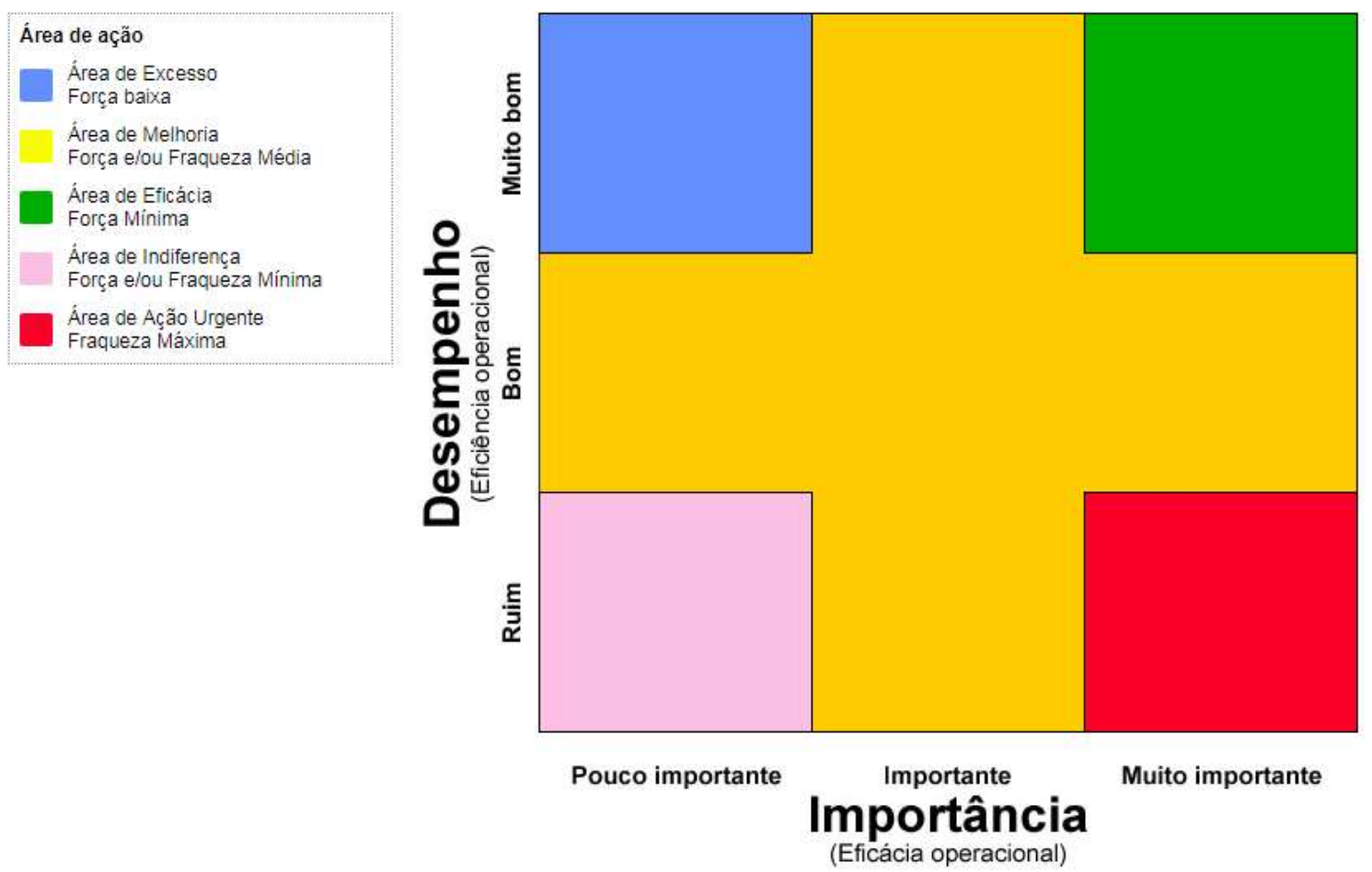

Fonte: Brasil (2014).

Tendo por base o diagnóstico e a matriz de identificação estratégica, salienta-se que dois pontos geram certo desconforto no que diz respeito à pretensão do projeto em ser sustentado pelas metodologias participativas. Primeiramente, que a ferramenta do diagnóstico é demasiadamente formal, engessada e relacionada à lógica empresarial de uma organização. Não se pretende aqui questionar a atuação nos mercados por parte das cooperativas de agricultores familiares, contudo, ao se analisar a densidade e o direcionamento das questões do diagnóstico, se nota o papel de mero fornecedor de informações, basicamente sobre a adoção ou não de tecnologias de gestão. Espera-se de um diagnóstico respaldado nas metodologias participativas que ele possa gerar discussões e problematizar a situação da cooperativa, gerar conhecimento com bases locais para o planejamento e o encaminhamento de atividades promotoras de mudanças na base atendida.

A segunda questão que gera desconforto é o fato de que o grau de importância atribuído para cada subárea foi proveniente do entendimento do técnico e não das discussões e do consenso entre os agentes beneficiários. Tal questão pode parecer irrelevante ou de pouca significância, contudo ao se perceber que uma dada subárea dotada de um desempenho "Ruim" pode passar da área de indiferença (cor de rosa) para a área de ação urgente (cor vermelha) a depender da opinião do técnico sobre a importância destas questões, contesta-se aqui novamente o caráter participativo da ferramenta em questão. Nesse sentido e de maneira a resumir a questão, é a opinião do técnico que direciona a área com desempenho ruim ou para ações 
urgentes ou para o esquecimento dentro do plano de aprimoramento.

\subsubsection{Plano de Aprimoramento}

Sobre o plano de aprimoramento nota-se que a recomendação é de que ele seja elaborado tendo por base a matriz de identificação estratégica, principalmente focando ações em áreas cujo desempenho da cooperativa esteja ruim e o grau de importância atribuído tenha sido muito importante. O plano de aprimoramento tem por objetivo:

apresentar ações a serem implementadas para solucionar os problemas de gestão dos empreendimentos, e especificamente de alguns processos fabris que por ventura estejam emperrando o processo produtivo; apresentar propostas de soluções para potencializar o acesso ao mercado e; apresentar propostas de gestão para cada área funcional em questão (DATER, 2012b, p. 07).

Ao se analisar este fragmento tem-se a impressão de que a participação dos agricultores e gestores das cooperativas deu-se até o momento de fornecer as respostas (sim, não, parcial e não se aplica) para as questões do diagnóstico, a partir dai atribuir grau de importância para as subáreas e propor ações no plano de aprimoramento cabe ao técnico extensionista, principalmente ao se analisar os verbos presentes nos objetivos deste documento: apresentar ações, apresentar propostas de solução e proposta de gestão. Reforça este entendimento o fragmento que diz que

Para cada problema e/ou fragilidade diagnosticada a equipe técnica multidisciplinar, deverá propor soluções, com procedimentos e prazos para a sua aplicação. As soluções deverão apresentar coerência com todas as áreas funcionais (DATER, 2012b, p. 07).

Também, norteará o atendimento da equipe técnica que se dará em dois tipos: i) atuação no empreendimento, apontando soluções a serem implementadas pela equipe; e ii) capacitação dos gestores/colaboradores das cooperativas através de cursos ministrados pela equipe técnica. O propósito destes cursos é transferir a tecnologia de gestão proposta para os empreendimentos em questão (DATER, 2012b, p. 07).

A partir do Plano de Aprimoramento a equipe técnica multidisciplinar deverá definir e elaborar um Plano de Trabalho para as ações e soluções que deverão ser realizadas (DATER, 2012b, p. 08).

Caberá a equipe técnica o mapeamento e articulação prévia dos atores/oportunidades de interesse para esse momento (DATER, 2012b, p. 08).

Ao se avaliar também estes fragmentos se nota a centralidade dada ao técnico e a preterição aos saberes e as capacidades dos gestores e agricultores destes empreendimentos. Propor e apontar soluções, transferir tecnologias de gestão, definir e elaborar planos de trabalho e realizar mapeamento de atores e oportunidades são incumbências dos técnicos extensionistas, situação esta que novamente afasta a proposta metodológica do projeto dos princípios participativos da extensão rural.

Sobre as visitas técnicas, tem-se em edital que "é neste momento, que efetivamente se dará a implementação do sistema de assistência técnica (Mais Gestão) elaborado a partir das deficiências, gargalos e potencialidades levantados junto aos empreendimentos" (DATER, 2012b, p. 08). Ao se avaliar o emprego do termo "levantados", pode-se atribuir um caráter de passividade do agente beneficiário, cujo papel reservado é o de informante, de repositório de informações, as quais quando coletadas pelos técnicos dotados de conhecimento científico ou vivências práticas irão tratá-las e propor a melhor maneira para resolver esta situação, tida como ineficiente perante as ferramentas de avaliação do projeto.

Talvez para dotar todo o projeto de uma fagulha participativa, tem-se em seu cronograma uma etapa proposta de avaliação do projeto. Tem-se que de fato é um dos únicos momentos em que os beneficiários aparecem como protagonistas, haja vista que para realizar esta atividade faz-se necessário a presença de no mínimo 50\% deles. Nota-se também que no edital 
se recomenda "que esta atividade ocorra em duas etapas: 1 etapa: envio da ficha de avaliação do projeto aos gestores dos empreendimentos assistidos que posteriormente deverão encaminhá-la a Coordenação do projeto" (DATER, 2012b, p. 09), avaliação esta que tinha por objetivo conhecer a percepção dos beneficiários sobre a metodologia, sobre a atuação da equipe de extensionistas e outros aspectos. Contudo não foi identificada a aplicação desta ferramenta em momento nenhum durante a realização do projeto.

Neste sentido, escolhe-se referenciar, dentre outros, o entendimento de Ávila et al. (2015) em um estudo onde atribuem o adjetivo de inovador ao "Mais Gestão", contudo, enfatizando o aumento da discricionariedade dos executores da política, chegando a chamá-los de burocratas de rua. Para os autores o "Mais Gestão" não se libertou da lógica das entregas de produtos e da atuação pré-definida, haja vista que estes indicadores se forjam como mensuradores de resultados do projeto.

Outro ponto que merece referência é a exigência que o edital faz para a construção de uma equipe multidisciplinar, “composta por técnicos de nível superior, a fim de atender aos princípios da Lei $\mathrm{n}^{\circ}$ 12.188/10 e o contido no art. $6^{\circ}$ do Decreto $\mathrm{n}^{\circ} 7.215 / 10$ ” (DATER, 2012b, p. 07). Nota-se que houve boas intenções para a composição de uma equipe que além de multidisciplinar fosse capaz de, minimamente, atender a diversas situações as quais poderiam se apresentar durante o atendimento dos empreendimentos, nesse sentido, além da formação multidisciplinar, nota-se o esforço que foi realizado pra buscar profissionais com vivência no cooperativismo e na realidade da agricultura familiar na localidade onde se pretendia atuar.

Ao se analisar o perfil dos profissionais demandados constata-se a solicitação de distintas formações, sendo elas na área de Gestão (Administração de empresas, Ciências econômicas, Gestão de Cooperativas, Gestão em Agronegócio, Marketing, Comunicação) área de Contabilidade/Finanças/Custos (Contabilidade, Ciências econômicas, Direito) e área de Produção (Engenharia de produção, Engenharia de alimentos, Agronomia, Nutrição, Veterinária, Zootecnia).

Contudo, ao se observar as cooperativas não unicamente por meio do aspecto instrumental e mercadológico, pode-se avaliar também a necessidade de atuação de outras formações, como economistas domésticos, psicólogos, pedagogos, cientistas sociais, engenheiros ambientais e outras cujos profissionais tem foco de atuação em aspectos sociais e ambientais e não unicamente econômicos. Estima-se que a composição da equipe com formações diversas não garantiu um atendimento multidisciplinar para as cooperativas, principalmente pelo fato de cada técnico ser o ponto focal de um determinado número de beneficiárias, inviabilizando sua atuação consistente em outros empreendimentos e também pelo tamanho dos lotes, os quais impunham um raio de atuação com demasiada distância geográfica entre as cooperativas, inviabilizando um acompanhamento multidisciplinar no dia-a-dia.

Em caráter de exemplificação segue o quadro $n^{\circ} 04$, no qual se apresenta o número de funcionários das cooperativas atendidas no Estado do Paraná. Esta informação pode dar elementos para a discussão da aplicabilidade do "Mais Gestão" nestes empreendimentos. Tendo por base que um dos objetivos do projeto foi implementar rotinas e tecnologias administrativas, supõe-se que a atuação de funcionários seja importante no alcance destes resultados, haja vista que por vezes o agricultor familiar integrante da gestão de um empreendimento não pode destinar tempo suficiente para estas ações e se manter ativo na base produtiva da cooperativa.

Por fim o gráfico a seguir traz elementos para discussão, principalmente ao se avaliar que 07 das 25 cooperativas atendidas no estado do Paraná não possuíam funcionário fixo, situação muito complexa no que diz respeito à implementação de todos as ferramentas preconizadas pelo "Mais Gestão". 


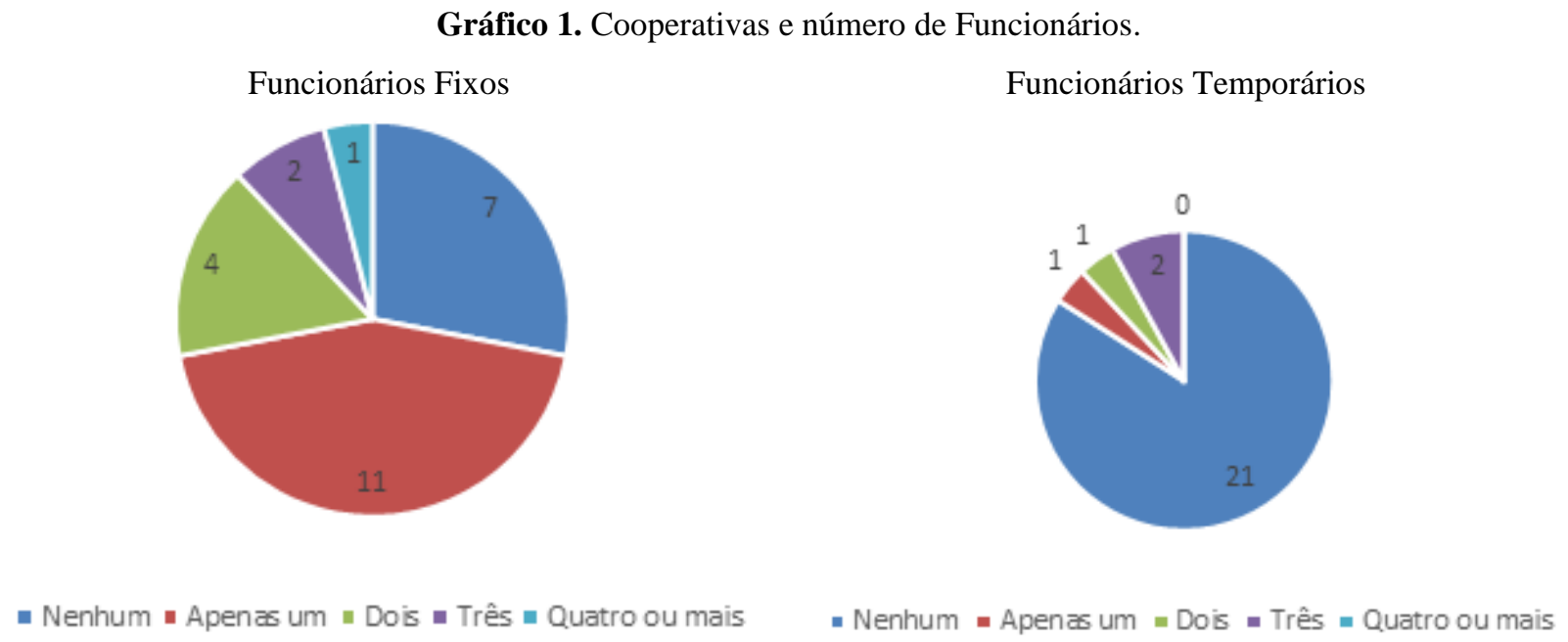

Fonte: Pesquisa (2017).

Também foram encontrados trabalhos que relatam estudos de casos sobre a realidade de algumas cooperativas atendidas pelo "Mais Gestão", como é o caso da dissertação realizada Gregolin (2015), focada especificamente na realidade das cooperativas no estado do Paraná. Neste estudo são apresentados os resultados da aplicação do projeto em 25 cooperativas e as conclusões dão conta de que boa parte delas não tinha pessoal disponível para a execução das práticas sugeridas pelo projeto, ficando o maior desafio não para o desempenho das tarefas e sim para a mobilização de pessoas, a princípio no quadro de cooperados, para exercerem o seu direito da participação e o dever da colaboração na gestão do empreendimento (Gregolin, 2015).

\subsection{Desafios para geração de metodologias específicas}

Um dos grandes debates atuais remete ao papel do técnico (e natureza dos aportes do conhecimento técnico-científico) na promoção da mudança almejada. No caso analisado frente a um referencial metodológico genérico (da PNATER) entendeuse importante diferenciar uma metodologia específica para o projeto "mais gestão". Neste âmbito cabe destacar os pressupostos inerentes a esta metodologia quanto ao valor do conhecimento técnico-científico.

Salienta-se que ao longo do tempo o extensionista teve seu papel revisto, deixando-o de ser o difusor do conhecimento técnico científico (papel desempenhado dentro da perspectiva proposta por Rogers) e passou a ser um agente dentro de um sistema denominado "sistema de inovação e conhecimento". Nesse sistema, composto por diversos atores e não unicamente pelo agricultor alvo da modernização e pelo extensionista arauto dos tempos modernos, cabe ao agente de ATER

facilitar os fluxos de informação e conhecimento dentro desse sistema, promovendo as interações entre produtores (como trocas de experiências) e destes com as organizações implicadas na geração de informações e conhecimentos úteis à resolução de seus problemas (Diesel, 2012, p. 42).

Contudo, embora o discurso genérico constante nos documentos do projeto remeta eventualmente a propostas que equivalem o papel do técnico à facilitação, observa-se um desenho operacional bastante centrado no uso de instrumentos de avaliação com alta dose de incorporação de conhecimentos técnico-científicos (caso do instrumento de diagnóstico), valorização da avaliação técnica (atribuição de importância relativa da subárea), da capacidade de recomendação técnica e centralidade do técnico no fazer pedagógico. Em suma, utilizou-se um instrumento para aferir o enquadramento de cada caso (cooperativa) numa matriz pré-definida de possibilidades e recomendou-se ações que concorrem para mudanças nestes aspectos de gestão propostos previamente pelo "programa” (reveladas nas questões do diagnóstico). A eficácia deste tipo de 
metodologia depende, fundamentalmente, da relativa homogeneidade dentre a organizações beneficiarias, visto que não pode contemplar possibilidades não previstas e devem estar de acordo quanto ao direcionamento proposto.

Porém, ao contrário disso, de acordo com Santos (2014) o campo onde se deu a execução do projeto "Mais Gestão" é demasiadamente heterogêneo e inclusive necessita de trabalhos que visem uma distinção legal entre as cooperativas tradicionais e as tidas como populares. Para o autor essa distinção é extremamente necessária para que as organizações de agricultores familiares possam, além de se reconhecer como empreendimentos populares, receber o apoio adequado, contingente as suas peculiaridades e princípios. Para Santos (2014) as cooperativas atendidas pelo projeto não aderiram ao mercado competitivo e guardam fortes características de empreendimentos populares e solidários. Nesse sentido, “deve-se reconhecer e levantar dados sobre as cooperativas rurais populares e a partir daí fomentar a educação autogestionária das cooperativas, promovendo a ascensão econômica atrelada à natureza rochdaliana social”' (Santos, 2014, p. 24).

\section{Considerações Finais}

Por meio destas leituras, chega-se ao ponto de acreditar, primeiramente, que não exista uma prática extensionista genuinamente alocada unicamente em um enfoque ou em outro, haja vista que as concepções das metodologias de ATER se encontram em constante transição e que por vezes, por mais que a instituição tenha um alinhamento, no final do processo há que se considerar o conhecimento, o alinhamento, a disponibilidade e o desempenho dos técnicos.

Conclui-se que por mais que os idealizadores deste projeto possam ter se munido de intenções participativas, ao analisar os documentos bases do "Mais Gestão" nota-se poucos aspectos participativos, principalmente tendo por base a análise dos objetivos, das ferramentas e das ações preconizadas. Acredita-se que o entendimento de Caporal (1991) sobre a prática dos extensionistas, onde para ele "muitos não sabem como mudar, querem mudar e acabam com a mesma prática" (Caporal, 1991, p. 54) também pode ser válido para os idealizadores deste projeto. Acreditar nisso é assumir que todo essa desvinculação com as metodologias participativas é resultado não de um desalinhamento com o enfoque e sim por, na janela de oportunidades de uma ação pública, não ter capacidade para pautar tais procedimentos.

Respaldando-se no entendimento de Armando et al. (1988), nota-se que houve emprego de uma metodologia cuja participação foi solicitada para "la obtención de información para diagnosticar los problemas del desarrollo rural" (Armando et al., 1988, p. 14) haja vista que a prática de diagnóstico veio pré-definida, com questões estabelecidas as quais direcionavam toda a intencionalidade do projeto. Para estes autores os diagnósticos precisam ser elaborados em conjunto, com "los actores sociales y los agentes externos, no sólo con la finalidad de identificar problemas particulares del medio rural, si no como una manera de apoyar iniciativas locales y de gestionar acciones de participación local” (Armando et al., 1988, p. 14).

Estudos podem ser realizados com o intuito de verificar a suposição apresentada aqui, de que o enfoque metodológico predominante no "mais gestão" não foi o participativo, e para isso sugere-se uma metodologia que leve em consideração a opinião dos técnicos, dos gestores e dos agricultores atendidos, haja vista que a materialização de uma ação extensionista está também relacionada a atuação destes agentes e não unicamente pelos materiais normativos.

Tendo por base as leituras realizadas e a observação empreendida em campo, acredita-se que o cooperativismo atendido pelo projeto se caracteriza mais como cooperativismo popular, de economia solidária ou de resistência do que como cooperativismo empresarial tradicional (Santos, 2014). Para alguns autores estas cooperativas possuem uma lógica racional coletivista ou substantiva, lógica esta que as colocam no mercado com uma visão diferenciada das que se constituem como cooperativas tradicionais (Christoffoli, 2000; Severo \& Pedrozo, 2008). Nesse sentido, conclui-se que as tratativas referentes a estas cooperativas deveriam ser diferentes das adotadas, provenientes de uma metodologia elaborada para atender empresas exportadoras a qual foi aplicada em um grupo de cooperativas, teoricamente dotadas de racionalidades distintas.

Ao se priorizar cooperativas que possuam estrutura organizacional para atender as demandas do mercado, 
principalmente as que já possuem experiência em comercialização, de certa forma o edital já faz um recorte para o seu público, o qual (principalmente em se tratando do segundo item) parece ser contemplado, contudo, ao se observar o perfil e a estrutura das cooperativas atendidas, nota-se que, se o pré-requisito era possuir estrutura para atender as demandas de mercado, houve equívocos de alguma parte na hora de escolher e mobilizar os beneficiários, haja vista que muitas delas se encontravam desprovidas de estrutura pessoal que absorvesse a gama de tecnologias de gestão disponibilizadas pelo projeto.

A importação da metodologia do "Mais Gestão" não favoreceu a sua execução nas cooperativas de agricultores familiares, por mais que tenha existido esforço para adaptá-la, acredita-se que não houve êxito nessa ação. Partindo dessa lógica, ousa-se afirmar que a metodologia da maneira em que foi proposta atenderia com muito mais eficiência o grupo de cooperativas cuja atuação no mercado é mais forte, geralmente, organizadas e representada pela OCB. Estas cooperativas comumente se apresentam com maior estrutura organizacional, maior atuação no mercado e consequentemente maiores possibilidades de absorção das tecnologias oferecidas. Por fim, porém não de maneira a encerrar o assunto e tampouco de maneira impositiva e taxativa, sugere-se: ou muda-se a metodologia como um todo ou se redireciona o foco do atendimento.

Como recomendação de estudos futuros, sugere-se a realização de estudos de casos em cooperativas assistidas, buscando avaliar a aplicação dos planos de aprimoramento, a realização das ações propostas, a avaliação dos beneficiários sobre o programa, bem como se a expectativa foi ou não atendida.

\section{Agradecimento}

Os autores agradecem as contribuições da Professora Dra. Vivien Diesel durante, non solum sed etiam, as disciplinas de Extensão Rural Avançada e Experiências em Extensão Rural. As discussões oriundas das referidas disciplinas contribuíram muito para redação deste trabalho. Contudo, como é de costume, toda a responsabilidade pelo que aqui se apresenta cabe aos autores.

\section{Referências}

Armando, C. et al. (1998) Los Métodos Del Diagnóstico Rural Rápido Y Participativo. Curso de Diagnóstico Rural Participativo El Rincón de Ademuz.

Avila, M. L. et al. (2015) Nova lei de ater e inovações em políticas públicas: o caso do programa mais gestão. In: $7^{\circ}$ Encontro Nacional da ANPPAS, Brasília. Anais do $7^{\circ}$ Encontro Nacional da ANPPAS.

Avila, M. L., Caldas, E. de L., \& Assad, S. S. (2013). Sinergia e coordenação em políticas públicas: o caso do PAA e PNAE. Sociedade e Desenvolvimento Rural, 7(3), 68-81.

Brasil. Lei $\mathrm{n}^{\circ}$ 5.764, de 16 de dezembro de 1971. Define a Política Nacional de Cooperativismo, institui o regime jurídico das sociedades cooperativas, e dá outras providências. < http://www.planalto.gov.br/ccivil_03/Leis/L5764.htm>.

Brasil. Lei no 8.666, de 21 de junho de 1993. Regulamenta o art. 37, inciso XXI, da Constituição Federal, institui normas para licitações e contratos da Administração Pública e dá outras providências. <www.planalto.gov.br/ccivil_03/leis/L8666cons.htm>. Acesso em: 12 jun. 2017.

Brasil. Lei $\mathrm{n}^{\circ}$ 12.188, de 11 de janeiro de 2010. Institui a política nacional de assistência técnica e extensão rural para a agricultura familiar e reforma agrária PNATER e o programa nacional de assistência técnica e extensão rural na agricultura familiar e na reforma agrária - PRONATER, altera a Lei no 8.666, de 21 de junho de 1993, e dá outras providências. < www.planalto.gov.br/ccivil_03/_ato2007-2010/2010/lei/112188.htm>. Acesso em: 12 jun. 2017.

Brasil. Ministério do Desenvolvimento Agrário. Mais Gestão. Sistema para geração de Matriz de Identificação Estratégica. 2014 <http://maisgestao.mda.gov.br/matrizes>

Caporal, F. R. (1991). A Extensão Rural e os limites à prática dos Extensionistas do serviço público. 1991. 221 f. 1991. Tese de Doutorado. Dissertação (Mestrado)-CPGER/UFSM.

Christoffoli, P. I. (2000). O desenvolvimento de cooperativas coletivas de produção de trabalhadores rurais no capitalismo: contradições, limites e possibilidades. 2000. 240 p. Dissertação (Mestrado e Administração) - Universidade Federal do Paraná, Curitiba/PR.

Coradin, C., \& Souza, R. S. de. (2017). Agroecologia por contrato, é possível? Revista nera, (37), 105-128.

Departamento de Assistência Técnica e Extensão Rural - DATER. Chamada pública para seleção de entidade de assistência técnica e extensão rural para qualificação da gestão, fortalecimento e inserção de cooperativas da agricultura familiar no Programa Nacional de Alimentação Escolar e outros mercados. Chamada Pública SAF/ATER n04/2012. Brasília, 2012a. 
Departamento de Assistência Técnica e Extensão Rural - DATER. Chamada pública para seleção de entidade de assistência técnica e extensão rural para qualificação da gestão de empreendimentos coletivos da agricultura familiar visando seu fortalecimento e inserção nos mercados institucionais e privados. Chamada Pública SAF/ATER n06/2012. Brasília, 2012b.

Departamento de Assistência Técnica e Extensão Rural - DATER. Chamada pública para seleção de entidade executora de assistência técnica e extensão rural para qualificação da gestão, e inserção de empreendimentos coletivos da agricultura familiar no programa nacional de produção e uso de biodiesel e outros mercados, nas regiões centro oeste, nordeste e semi-árido. Chamada Pública SAF/ATER n07/2012. Brasília, 2012c.

Departamento de Assistência Técnica e Extensão Rural - DATER. Chamada pública para seleção de entidade de assistência técnica e extensão rural para qualificação da gestão, fortalecimento e inserção de cooperativas da agricultura familiar nos mercados institucionais, públicos e privados. Chamada Pública SAF/ATER n ${ }^{\circ} 17 / 2013$. Brasília, 2013

Diesel, V. (2012). A construção de consensos sobre o futuro da extensão rural nas organizações de cooperação internacional. In: DIESEL, V., NEUMANN, P. S., CLAUDINO DE SÁ, V. Extensão rural no contexto do pluralismo institucional: reflexões a partir dos serviços de ATES nos assentamentos de reforma agrária no RS. Ijuí. Ed. UNIJUÍ, p. 35-57.

Diniz, P. C. O., Lima, J. R. T., \& Almeida, A. (2011). Chamadas públicas de ATER: primeiras reflexões. In: Congresso Internacional da Associação Latinoamericana De Sociologia. Anais eletrônicos. Recife: UFPE, p. 28.

Duarte, L. M. G., \& Wehrmann, M. E. S. de F. (2006). Histórico do cooperativismo agrícola no Brasil e perspectivas para a agricultura familiar. Associativismo, Cooperativismo e Economia Solidária no Meio Rural, p. 13.

Frantz, W. (2012). Associativismo, Cooperativismo Economia Solidária. Editora Unijuí.

Freitas, A. F. de, \& Freitas, A. F. de. (2011). Empreendimentos induzidos por políticas públicas: reflexões a partir do Programa de Combate à Pobreza Rural (PCPR) em Minas Gerais. Interações (Campo Grande), 12(2).

Gerhardt, T. E., \& Silveira, D. T. (2009). Métodos de pesquisa. PLAGEDER

Gil, A. C. (2008). Métodos e técnicas de pesquisa social. Atlas.

Gregolin, M. R. P. (2015). Diagnóstico de gestão em cooperativas da agricultura familiar no Estado do Paraná: limites e potencialidades em um modelo solidário e democrático. 2015. 149 p. Dissertação (Mestrado em Desenvolvimento Rural Sustentável) - Universidade Estadual do Oeste do Paraná, Marechal Cândido Rondon/PR.

Grisa, C., \& Wesz Junior, V. (2010). Políticas públicas para a agricultura familiar: entre avanços e desafios. Boletim do OPPA, (3), 1-4.

Lauschner, R. (1994). Cooperativismo e Agricultura Familiar. Mimeo, p.7

Marconi, M. de A., \& Lakatos, E. M. (2003). Fundamentos de metodologia científica. (5a ed.), Atlas.

Mendonça, S. R. (2005). Estado e hegemonia do agronegócio no Brasil. Revista História \& Perspectivas, 1,(233).

Project Management Institute (PMI). (2013). Um Guia do Conhecimento em Gerenciamento de Projetos (Guia PMBOK®). Pennsylvania: Project Management Institute, In.

Rech, D. (2012). Formação de agentes de comercialização das bases de serviços: cooperativismo e associativismo. Brasília: Instituto Novas Fronteiras da Cooperação.

Rothschild-Whitt, Joyce. (1979). The collectivist organization: An alternative to rational-bureaucratic models. American Sociological Review, p. 509-527.

Santos, A. P., \& Silva, M. G. (2015). Análise do processo de constituição da união das coopeartivas de agricultura familiar e economia solidária em Minas Gerais. IV Congresso da Rede Universitária de Incubadoras Tecnológicas de Cooperativas Populares e II Simpósio Internacional de Extensão Universitária e Economia Solidária. Salvador - BA. De 15 a 18 de abril de 2015. <http://ites.colivre.net/bin/view/Site/Projeto16>. Acesso em: 15 set. 2017.

Santos, R. N. F. dos. (2014). Desafios a serem superados pelo Programa Mais Gestão nas cooperativas de agricultores familiares no Brasil. 2014.28 p. Monografia (Graduação em Gestão do Agronegócio) - Universidade de Brasília, Planaltina/DF.

Severo, L. S., \& Pedrozo, E. Á. (2008) A citricultura orgânica na região do Vale do Caí (RS): racionalidade substantiva ou instrumental? RAM. Revista de Administração Mackenzie, 9(2), 58-81.

Silva, M. W. D. da. (2006). Possibilidades e limites do cooperativismo pelo prisma de entidades de representação das cooperativas: uma análise comparativa entre a Organização das Cooperativas do Estado de São Paulo (OCESP) e a União e Solidariedade das Cooperativas e Empreendimentos de Economia Social do Brasil (UNISOL/Brasil). 113 p. Dissertação (Mestrado em Sociologia) - Universidade de São Paulo, São Paulo.

Sousa. C. S. (2015). Análise da concepção do programa mais gestão: Entre desenvolvimento e desafios, 2015.61 p. Monografia (Graduação em Gestão Ambiental) - Universidade de Brasília, Planaltina/DF. 